\title{
Vorrede zur sechsten Auflage.
}

Die stetigen Fortschritte der Wissenschaft, und die Fortschritte, welche man selbst macht, so lange man noch Lust und Kräfte hat, mit dem Strom mitzuschwimmen, kann man nicht besser bemessen, als wenn man genöthigt ist, eigene ältere Arbeiten von Zeit zu Zeit zu überarbeiten. Ich habe diesem Gedanken schon früher bei gleicher Veranlassung einmal Ausdruck gegeben, scheue mich indess nicht, ihn hier zu wiederholen, weil dieses Bewusstsein des Fortschreitens uns ein Trost in den vielen trüben Stunden ist, in welchen uns bei dem eifrigsten Bestreben, unsern leidenden Mitmenschen $z u$ helfen, die Ohnmacht unseres Wissens und Könnens schwer darniederdrückt.

So viel es in meinen Kräften stand, habe ich gethan, dies Buch wieder auf den jetzigen Standpunkt unseres Wissens zu erheben; sowohl an der Form wie am Inhalt zu bessern, bin ich nicht müde geworden; der Abschnitt über Verkrümmungen ist ganz neu geschrieben; veraltete Holzschnitte sind durch bessere ersetzt, auch manche neue Abbildungen sind hinzugefügt; die Receptformeln sind auch in Grammes angegeben, doch 
sind sie nicht einfach umgerechnet, sondern es ist nur ungefähr die gleiche Dosirung inne gehalten und die Hauptintention darauf gerichtet, auch in der neuen Form für's Gedächtniss leicht zu bchaltende Verhältnisse aufzustellen.

Möge auch diese auf Wunsch des Herrn Verlegers erheblich verstärkte Auflage wohlwollend aufgenommen werden und der Jugend Freude am Studium der Chirurgie erwecken!

Wien, Anfang November 1872.

Th. BilIroth. 